A SPECIAL ISSUE FOR THE $6^{\text {TH }}$ SCIENTIFIC INTERNATIONAL CONFERENCE

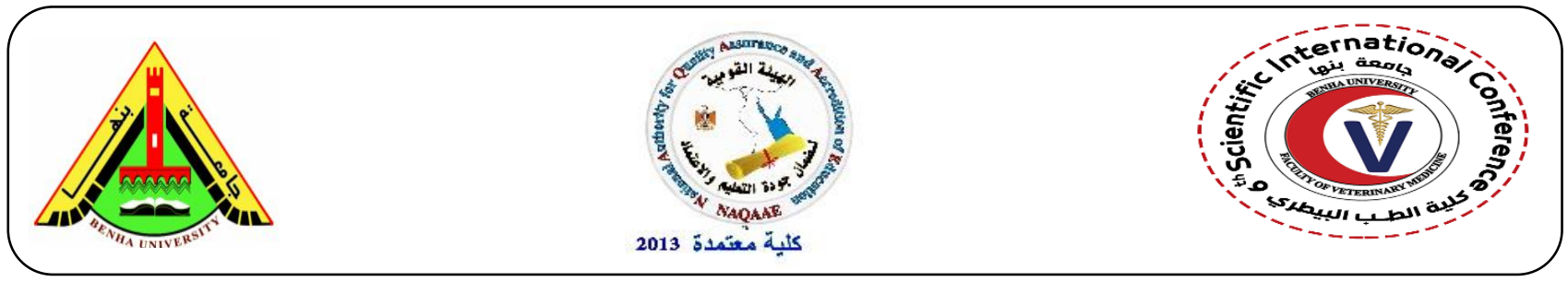

\title{
The Ameliorative Effect of Proanthocyanidins against Streptozotocin Induced Diabetic Nephropathy in Rats
}

\author{
Samy A. Hussein*; Mohamed R. R. Hassanein and Maher A. Awadalla \\ Department of Biochemistry, Faculty of Vet. Med., Benha University, Egypt. \\ *Corresponding author: Samy Ali Hussein; email: samyaziza@yahoo.com
}

\section{A B S T R A C T}

Diabetic nephropathy (DN) is an important microvascular complication of diabetes and one of the main causes of end stage renal disease. The protective effect of grape seed proanthocyanidins extract (GSPE) against streptozotocin (STZ) induced diabetic nephropathy and oxidative stress in rats was evaluated. Seventy two male albino rats divided into four groups. Group I (normal group): rats administered buffer citrate. Group II (DN group): rats received a single intraperitoneal (i.p) injected dose of STZ (50 mg/kg b.wt). Group III (DN + insulin treated group): diabetic nephropathy rats treated with insulin (2U/rat/day/i.p). Group IV (DN + GSPE treated group): diabetic nephropathy rats treated with GSPE ( $250 \mathrm{mg} / \mathrm{kg}$ b.wt/day/orally). The obtained results showed a significant increase in serum glucose, urea, creatinine and kidney tissue L-MDA concentrations with upregulation of NF-kB gene expression in diabetic nephropathy induced rats. However, SOD activity and GSH level of kidney tissues were markedly decreased. Administration of GSPE to DN induced rats caused a significant improvement of all previous parameters towards their normal ranges. These results suggested that, GSPE treatment may have a therapeutic effect against STZ-induced diabetic nephropathy and oxidative stress in rats through free radical scavenging and anti-inflammatory activity as well as regenerating endogenous antioxidant defense system mechanisms.

Key words: Streptozotocin, GSPE, oxidative stress, diabetic nephropathy.

(http://www.bvmj.bu.edu.eg)

(BVMJ-34(3):42-56, 2018)

\section{INTRODUCTION}

Diabetes mellitus is a group of metabolic alterations characterized by hyperglycemia resulting from defects in insulin secretion, action or both. Chronic hyperglycemia of diabetes is associated with long-term damage, dysfunction and eventually the failure of organs especially the eyes, nerves, heart, blood vessels and kidneys (Huang et al., 2005). Type II diabetes mellitus developed by metabolic abnormalities such as impaired insulin secretion, increased hepatic glucose production and decreased insulinstimulate of glucose uptake in peripheral tissues (Kakadiya et al., 2010). 
Diabetes is usually accompanied by an increased production of reactive oxygen species (ROS) and free radicals or by impaired antioxidant defenses which are widely accepted as important in the development and progression of diabetic complications (Kumar et al., 2006). The increased risk of complications occurred particularly in subjects with poor glycaemic control (Gavin et al., 1997). In addition, diabetes causes increased oxidative stress in various tissues as evidenced by increased levels of oxidized DNA, proteins and lipids which are thought to play an important role in the pathogenesis of various diabetic complications (Chung et al., 2003). In diabetic patients with vascular complications, there are significant changes such as increased lipid peroxidation, dyslipidemia and irregularities in the metabolism of proteins, carbohydrates and lipids. Increased lipid peroxidation is accepted to be one of the main causes of diabetic complications (Gallou et al., 1994).

Diabetic nephropathy (DN) is a leading cause of end-stage renal failure worldwide. Its morphological characteristics include glomerular hypertrophy, basement membrane thickening, mesangial expansion, tubular atrophy, interstitial fibrosis and arteriolar thickening. All of these are part and parcel of microvascular complications of diabetes. A large body of evidence indicates that oxidative stress is the common valuable link for the major pathways involved in the development and progression of diabetic microvascular as well as macrovascular complications of diabetes. Several lines of evidence suggest the central role of oxidative stress in the development of DN and the beneficial effects of antioxidants in renal injury owing to diabetes (Bagchi and Puri, 1998).Traditionally, DN has been described as a glomerular disease with five different stages are glomerular hyperfiltration, incipient nephropathy, microalbuminuria, overt proteinuria and end-stage renal disease (Mogensen et al., 1983).

STZ is a glucosamine-nitrosouria compound that causes damage and destruction of $\beta$-cells primarily through nitric oxide mediated DNA damage. It enters $\beta$-cells via the reduced glucose transporter type 2 (GLUT-2 transporter) to which it binds readily due to its similarity in structure to glucose (Kaneto et al., 1995). STZ is toxic to the insulin producing beta cells of the Islets of Langerhans in the pancreas so it is widely employed to induce experimental diabetes in animals. It damages the DNA of pancreatic- $\beta$ cells and triggers multiple pathways including activation of protein kinase-C, poly (ADPribose) polymerase and $\mathrm{NAD}(\mathrm{P}) \mathrm{H}$ oxidase with consequent generation of ROS and advanced glycation end products resulting in renal damage and nephropathy (Haidara et al., 2008).

Flavonoids are phenolic phytochemicals have various effects on protecting cellular components against ROS (Hertog and Hollman, 1996). Their antiradical property is directed towards highly reactive species implicated in the initiation of lipid peroxidation. Moreover, flavonoids are soluble chain-breaking inhibitors of the peroxidation process, scavenging intermediate peroxyl and alkoxyl radicals (Jovanovic et al., 1998). GSPE has a protective effect on various forms of cardiac disorders, reduce hypoxicischemic brain injury, protect gastric mucosa and prevent diabetic nephropathy from progressing (Mansouri et al., 2015).

GSPE increased the activity of antioxidant enzymes (Gao et al., 2014) and decreased the amount of iNOS, NFkB, TNF- $\alpha$ and caspase- 3 in the kidney (Nazima et al., 
2015).This study was to investigate the possible beneficial effect of GSPE against deleterious effect of diabetic nephropathy induced in male rats through investigation of blood glucose, kidney functions, inflammatory and oxidative stress biomarkers.

\section{MATERIALS AND METHODS:}

\subsection{Experimental animals:}

Seventy two white male albino rats of 5-6 weeks old and weighing $180-200 \mathrm{~g}$ were used in this study. Rats were housed in separated metal cages and kept at constant environmental and nutritional conditions throughout the period of experiment. The rats were fed on constant ration and fresh, clean drinking water was supplied ad-libitum. All rats were acclimatized for minimum period of 15 days prior to the beginning of study.

\subsection{Chemicals and antioxidant:}

All chemicals were of analytical grade and obtained from standard commercial suppliers .The antioxidant and chemicals used in the present study were:

a- Streptozotocin: STZ [2-deoxy-2-(3-methyl3-nitrosoureido)-D-glucopyranose], was purchased from (Sigma Chemical Co. P.O. Box. 14508, St. Lowis, U.S.A.). Freshly dissolved in citrate buffer, $\mathrm{PH} 4.5$ and administered intraperitoneally as a single injected dose of (50 mg $/ \mathrm{kg}$ body wt.) (Ramanathan et al., 1999).

b- Grape Seed Proanthocyanidins Extract: GSPE was purchased from (Al Debeiky Pharma Company for Pharmaceutical industries, Al Obour, Cairo, Egypt). It was dissolved in DIMSO and administered orally to rats at a dose level of $(250 \mathrm{mg} / \mathrm{kg} \mathrm{b} . \mathrm{wt})$ once daily for 6 weeks (Bagchi et al., 2001).

c- Other chemicals used in this study were of the highest purified grades available purchased from El Gomhouria Company for Trading Chemicals and Medical Appliances, Egypt.

\subsection{Experimental design:}

After acclimatization to the laboratory conditions, the animals were randomly divided into four groups placed in individual cages and classified as following:

Group I (normal control group): Consists of 12 rats, received no drugs, served as control non- treated for all experimental groups.

Group II (DN induced group): Consists of 24 rats, received STZ as a single intraperitoneally injected dose of $(50 \mathrm{mg} / \mathrm{kg}$ b.wt).

Group III (DN + insulin treated group): Consists of 18 rats, received STZ and after 8 weeks treated daily with insulin $(2 \mathrm{U} /$ rat per day/i.p) for 6 weeks.

Group IV (DN + GSPE treated group): Consists of 18 rats, received STZ and after 8 weeks treated daily with GSPE $(250 \mathrm{mg} / \mathrm{kg}$ b.wt/ orally) for 6 weeks.

\subsection{Sampling:}

\subsubsection{Blood samples:}

Blood samples were collected by ocular vein puncture from all animal groups, at the end of experiment, after 14 weeks in dry clean tubes and allowed to clot for 30 minutes and serum was separated by centrifugation at 3000 r.p.m for 15 minute. The serum was taken by automatic pippet and received in dry sterile tubes and used directly for determination of blood glucose, urea and creatinine concentrations according to the method described by Tietz, (1995), Tietz, (1990) and Tietz, (1986).

\subsubsection{Tissue samples:}

About $0.5 \mathrm{~g}$ of kidney tissue specimen was taken from all animal groups (control and 
experimental groups) once after the end of 14 weeks.

\subsection{Biochemical analysis:}

\subsubsection{Kidney tissue for biochemical analysis}

Briefly, kidney tissues were cut, weighed and minced into small pieces, homogenized with a glass homogenizer in 9 volume of ice-cold $0.05 \mathrm{mM}$ potassium phosphate buffer ( $\mathrm{pH}$ 7.4) to make $10 \%$ homogenates. The homogenates were centrifuged at 6000 r.p.m for 15 minutes at $4{ }^{\circ} \mathrm{C}$ then the resultant supernatant was used for the determination of the following parameters: SOD, GSH and L-MDA according to the method described by Kakkar et al., (1984), Paglia and Valentine, (1967) and (Mesbah et al., 2004) respectively.

\subsubsection{Kidney tissue for molecular analysis}

About 0.5 of kidney tissue put in eppendorf tubes and were immediately kept in liquid nitrogen and stored at $-80^{\circ} \mathrm{C}$ till RNA extraction for determination of NF-kB gene expression by real-time quantitative polymerase chain reaction (real- time qPCR) analysis in kidney of rats. Target gene was was normalized with $\beta$-actin by used the $2^{-}$ ${ }^{\Delta \Delta \mathrm{Ct}}$ method (Livak and Schmittgen, 2001).

Forward and reverse primers sequence for real time PCR.

\begin{tabular}{lll}
\hline \multirow{2}{*}{ Gene } & Forward primer & Reverse primer \\
& $\left({ }^{\prime} 5-----^{\prime} 3\right)$ & $\left({ }^{\prime}-----{ }^{\prime 3}\right)$ \\
$N K-k B$ & CCTAGCTTTCTCTGAACTGCAAA & GGGTCAGAGGCCAATAGAGA \\
$\beta$-actin & ACCCACACTGTGCCCATCTA & CGTCACACTTCATGATG \\
\hline
\end{tabular}

\subsection{Statistical analysis:}

The results were expressed as mean \pm SE using SPSS (13.0 software, 2009) program. The data were analyzed using oneway ANOVA to determine the statistical significance of differences among groups. Duncan's test was used for making a multiple comparisons among the groups for testing the inter-grouping homogeneity. Values were considered statistically significant when $\mathrm{p}<0.05$.

\section{RESULTS:}

The obtained data presented in table (1) revealed that, STZ-induced diabetic nephropathy rats showed a significant increase in serum glucose, urea and creatinine concentrations compared to normal control group.
GSPE treatment to STZ-induced diabetic nephropathy rats caused a significant decrease in elevated serum glucose, urea and creatinine concentrations when compared with STZ-induced diabetic nephropathy non treated group.

The obtained results presented in table (2) revealed that, STZ-induced diabetic nephropathy rats showed a significant increase in kidney tissue L-MDA with significant upregulation of NF-kB and significant decrease in SOD activity and GSH level compared to normal control group.

GSPE treatment to STZ-induced diabetic nephropathy rats caused a significant decrease in kidney tissue L-MDA with a significant down-regulation of NF-kB and a 
significant increase in SOD activity and GSH

level compared to STZ-induced diabetic

nephropathy non treated group.

Table (1): Effect of GSPE administration on serum glucose, urea and creatinine concentrations in streptozotocin induced diabetic nephropathy rats (mg/dl).

\begin{tabular}{lccc}
\hline $\begin{array}{l}\text { Parameters } \\
\text { Exp. Groups }\end{array}$ & Glucose $(\mathrm{mg} / \mathrm{dl})$ & Urea $(\mathrm{mg} / \mathrm{dl})$ & Creatinine $(\mathrm{mg} / \mathrm{dl})$ \\
\hline $\begin{array}{l}\text { Group I: } \\
\text { Normal control }\end{array}$ & $93.33 \pm 4.03^{\mathrm{e}}$ & $26.15 \pm 0.86^{\mathrm{d}}$ & $0.91 \pm 0.01^{\mathrm{d}}$ \\
Group П : & $317.33 \pm 9.19^{\mathrm{a}}$ & $46.18 \pm 1.49^{\mathrm{a}}$ & $1.6 \pm 0.03^{\mathrm{a}}$ \\
Control DN group & & & \\
Group III: & $159.33 \pm 5.19^{\mathrm{d}}$ & $29.47 \pm 0.94^{\mathrm{c}}$ & $0.98 \pm 0.03^{\mathrm{c}}$ \\
DN + Insulin & & & \\
Group IV: & $204.60 \pm 6.68 \mathrm{c}$ & $31.83 \pm 0.44^{\mathrm{c}}$ & $1.14 \pm 0.06^{\mathrm{c}}$ \\
DN+ GSPE & & & \\
& & & \\
\end{tabular}

Data are presented as $($ Mean \pm S.E). $\quad$ S.E $=$ Standard error.

Mean values with different superscript letters in the same column are significantly different at $(\mathrm{P} \leq 0.05)$.

Table (2): Effect of GSPE administration on kidney tissue SOD activity, GSH, LMDA levels and NF-kB gene expression in streptozotocin induced diabetic nephropathy rats.

\begin{tabular}{|c|c|c|c|c|}
\hline Exp. Groups & $\begin{array}{l}\text { SOD } \\
\text { (IU/g tissue) }\end{array}$ & $\begin{array}{l}\text { GSH } \\
\text { (IU/g tissue) }\end{array}$ & $\begin{array}{l}\text { L-MDA } \\
\text { nmol/g tissue }\end{array}$ & $\begin{array}{l}\text { Fold change in } \\
\text { NF-kB gene } \\
\text { expression }\end{array}$ \\
\hline Group I: & $0.96 \pm 0.04^{\mathrm{a}}$ & $20.00 \pm 0.95^{\mathrm{a}}$ & $38.67 \pm 1.28^{\mathrm{e}}$ & $1.00 \pm 0.01^{\mathrm{e}}$ \\
\hline \multicolumn{5}{|l|}{ Normal control } \\
\hline Group $\Pi$ : & $0.18 \pm 0.01^{\mathrm{e}}$ & $5.40 \pm 0.78^{\mathrm{d}}$ & $95.80 \pm 3.42^{\mathrm{a}}$ & $10.06 \pm 0.35^{\mathrm{a}}$ \\
\hline \multicolumn{5}{|c|}{ Control DN group } \\
\hline Group III: & $0.78 \pm 0.03^{b}$ & $15.20 \pm 0.70^{\mathrm{b}}$ & $51.50 \pm 1.10^{\mathrm{d}}$ & $2.55 \pm 0.14^{\mathrm{d}}$ \\
\hline \multicolumn{5}{|l|}{ DN+ Insulin } \\
\hline Group IV: & $0.62 \pm 0.03^{\mathrm{C}}$ & $13.10 \pm 0.68^{b}$ & $66.63 \pm 1.20^{c}$ & $4.03 \pm 0.11^{\mathrm{C}}$ \\
\hline DN+ GSPE & & & & \\
\hline
\end{tabular}

Data are presented as (Mean \pm S.E). $\quad$ S.E $=$ Standard error.

Mean values with different superscript letters in the same column are significantly different at $(\mathrm{P} \leq 0.05)$. 


\section{DISCUSSION:}

Chronic hyperglycemia in the kidney stimulates the production of AGEs, the polyol pathway and activation of protein kinase $\mathrm{C}$ (PKC) which lead to increased ROS formation and oxidative stress (Pacher et al., 2005). Renal cells (glomerulus, tubules and fibroblasts) express NADPH oxidase and contribute to ROS formation in small amounts in the healthy state. In chronic hyperglycemia the dysfunctional renal cells can increase ROS generation which may enhance renal tissue injury (Shiose et al., 2001). In addition to structural and functional derangements the presence of excessive ROS in the renal milieu can promote dysregulation of renal medullary blood flow leading to renovascular hypertension that help in progression of diabetic nephropathy (Chabrashvili et al., 2002).

Presented findings showed that, a significant increase in serum glucose concentration was observed in STZ-induced diabetic nephropathy rats. These results are nearly similar to those reported by Akbarzadeh et al., (2007) who reported that, serum glucose levels was elevated three-fold in the diabetic animals group compared to normal who added that, Hyperglycemia, hypoinsulinemia, polyphagia, polyuria and polydipsia accompanied by weight loss were seen in adult rats within three days of STZ treatment which indicates irreversible destruction of Langerhans islets cells. Moreover, glucose metabolism through harmful alternate pathways such as via protein kinase $\mathrm{C}$ activation and advanced glycation end-products formation is reported to contribute to the development of diabetic nephropathy (Ha et al., 2008). and increased oxidative stress with subsequent alterations in celluar redox balance (Williamson et al., 1993).
Treatment with GSPE to diabetic nephropathy rats significantly decreased elevated serum glucose level in STZ-induced diabetic nephropathy rats after 6 weeks from the onset of treatment with GSPE. These results are nearly similar to those recorded by Lee et al., (2008) and Bao et al., (2015) who reported that, GSPE has antihyperglycemic properties and after 8 weeks of treatment of diabetic nephropathy rats with GSPE significantly controlled the body weight loss compared to control diabetic nephropathy group. Also, Sayed, (2012) reported that Treatment with GSPE to diabetic nephropathy rats significantly decreased elevated serum glucose level in STZ-induced diabetic nephropathy rats compared to control diabetic nephropathy group. The hypoglycemic effect of GSPE could be attributed to different mechanisms that include increasing of insulin sensitivity in type-2 diabetic patients (Sayed, 2013), direct binding site at the tyrosine kinase domain of the insulin receptor (Jacob et al., 1999), increasing glucose transporter-4 in the cell membrane (Pinent et al., 2004) and/or restore the normal architecture and function of $\beta$ - cells (Abir El-Alfy et al., 2005).

The obtained results showed that, a significant increase in serum urea and creatinine concentrations were observed in STZinduced diabetic nephropathy rats These results are nearly similar to those reported by (Sayed, 2012) and (Akram Ahangarpour et al., 2016) who reported that, diabetic nephropathy significantly increased serum urea and creatinine in the untreated diabetic nephropathy group in comparison with the non-diabetic nephropathy control group. Also, Lal et al., (2009) reported that, all diabetics have higher blood urea level, and has significantly higher uric acid level as compared to non-diabetic subjects due to 
continuous catabolism of amino acids high urea will be formed from urea cycle.

Urea is the one of the waste product excreted by the kidney and main end product of protein metabolism. An elevation of blood urea usually signifies decreased renal function (Sakami and Harrington, 1963). Moreover, (Ismail and Abd El-Gawad, 2010) demonstrated that, increase levels of serum uric acid, urea nitrogen and creatinine concentrations were observed in diabetic rats.Also, Bhatti et al., (2005) reported that, Urine albumin excretion increased by three fold with no change in plasma creatinine levels in the diabetic rats non-treated group.

Administration of GSPE to STZinduced diabetic nephropathy rats significantly decreased serum urea and creatinine concentrations. These results are nearly similar to those reported by (Sayed, 2012) and (Liu et al., 2006) who reported that, GSPE administration showed a significant reduction in serum creatinine and urea levels, decreasing proteinuria and attenuating the progression of nephropathy in diabetic rats.

Presented findings showed that, a significant decrease in kidney SOD activity was observed in STZ-induced diabetic nephropathy rats. These results are nearly similar to those reported by Daniel et al., (2015) and Kedziora-Kornatowska et al., (2000) who recorded that, reduced kidney activity of SOD three to six weeks after STZ administration compared to control group. Also, Mohora et al., (2006) reported that, increased level of MDA and low SOD activity are found in diabetes which confirmed the involvement of oxidative stress in renal injury induced in diabetic rats.

DN is a serious and important microvascular complication that occurs frequently in patients with diabetes. The pathogenetic mechanisms for the microvascular complications may be associated with oxidative stress which is regarded as the major factor that couples hyperglycemia with vascular complications. Oxidative stress causes an increase of ROS which can attack at various target organ systems (Papaharalambus and Griendling, 2007). Treatment with GSPE to STZ-induced diabetic nephropathy rats significantly increased kidney SOD activity. These results are nearly similar to those reported by Mansori et al., (2011) and Sayed, (2012) who reported that, GSPE treatment showed a significant increase in SOD activity compared to diabetic nephropathy group. Also, GSPE showed a protective effect on experimental diabetic nephropathy due to inhibition of AGEs formation correlated with its antioxidant activites (liu et al., 2006), and the excellent free radical scavenging activity of GSPE is a reason for this reversal effect of lipid peroxidation level and antioxidant enzymes activities (Bagchi et al., 1997).

The obtained results showed that, a significant decrease in kidney reduced glutathione concentration was observed in STZ-induced diabetic nephropathy rats compared to control rats, similar results were recorded by Jagdish et al. (2010) and Jagdish and Nehal, (2011) who demonstrated that, renal ischemia/reperfusion $\mathrm{I} / \mathrm{R}$ group of diabetic rats showed significantly decreased enzymatic activity of SOD, CAT and GSH when compared with the sham control rats. Glutathione provide a first line of defense against ROS, as it can scavenge free radicals and reduce $\mathrm{H}_{2} \mathrm{O}_{2}$. The decreased concentration of GSH in kidney might be due to NADPH depletion or GSH consumption in the removal of peroxide (Gumieniczek, 2005). The ratio of reduced glutathione/oxidized glutathione is one of many cellular redox couples that directly contribute to redox status. Depletion of reduced GSH either by conjugation and removal from the cell or oxidation to GSSG could significantly affect the overall redox potential of the cell (Yadav 
et al., 1997). GSH-dependent enzymes provide a second line of defense as they primarily detoxify noxious by products generated by ROS and also help to prevent propagation free radicals (Gumieniczek, 2005). Alsaif (2009) reported that, GSH/GSSG (Reduced glutathione and Oxidized glutathione) ratio were found to be lowest in the kidney of diabetic rats group. Some workers (Obrosova et al., 2003) reported that, the concentrations in the diabetic kidney were found to be significantly reduced, suggesting that the reduced GSH concentrations may play a role in the development of diabetic complications.

GSPE administration to STZ-induced diabetic nephropathy rats showed a significant increase in kidney reduced glutathione when compared with diabetic nephropathy non treated group. These results are nearly similar to those obtained by Bagchi et al., (2000) who reported that, GSPE treatment significantly increased GSH level compared to the positive control group because GSPE functions as a free radical scavenger and therefore increase the available free GSH which detoxify the reactive intermediary oxygen products of lipid peroxidation. The role of oxidative stress in the pathogenesis of diabetic nephropathy is not only through over production of ROS, but also through auto-oxidation of glucose, reduction of antioxidant enzyme activities, impaired glutathione metabolism, formation of lipid peroxides and non-enzymatic protein glycosylation (Toba et al., 2009).

Presented findings showed that, a significant increase in kidney L-MDA concentration, a marker of lipid peroxidation in STZ-induced diabetic nephropathy rats in comparison with the control normal group. Lipid peroxidation is a marker of cellular oxidative damage initiated by ROS (Farber et al., 1990). These results are nearly similar to those reported by Bukan et al., (2003),
Siddiqui et al., (2011) and Erejuwa, (2012) who recorded a significant increase in kidney L-MDA of experimentally induced diabetes in animals. This increase in the kidney L-MDA indicated enhanced lipid peroxidation which could cause injury to the cells. Increased levels of lipid peroxides in the plasma are usually considered to be the consequence of high production and liberation of tissue lipid peroxides into circulation due to pathological changes (Al-Faris et al., 2010). Hyperglycemia leads to generation of free radicals due to auto-oxidation of glucose and glycosylation of proteins (Tirgar et al., 2010). And induces oxitative stress which becomes the chief factor that leads to diabetic complications (Shuklak et al., 2012). Abnormal elevated levels of free radicals and the simultaneous reduction of antioxidant defense can result in damage of cellular organelles and enzymes, increased lipid peroxidation and development of insulin resistance (Kumar et al., 2012). The elevated level of lipid peroxidation causes oxidative damage by increasing peroxy radicals and hydroxyl radicals (Singh et al., 2012), and is usually measured through the catabolite, malonaldehyde (MDA) in terms of TBARS as a marker of lipid peroxidation (KedzioraKornatowska et al., 2000). Also, increased lipid peroxide may be due to the increased glycation of protein in diabetes mellitus. The glycated protein might themselves act as a source of free radicals. There is a clear association between lipid peroxide and glucose concentration which may be also thought to play a role in increased lipid peroxidation in diabetes mellitus (Suryawanshi et al., 2006).

Oxidative stress is considered as an imbalance between oxidants and antioxidants. The accumulated ROS could interact with polyunsa- turated fatty acids leading to the formation of lipid peroxidation in kidney 
tissues and consequently result in damage or toxicity (Alarcon-Aguilar et al., 2010). It is widely acknowledged that oxidative stress is the major factor of diabetic complications including diabetic nephropathy (Rolo and Palmeira, 2006). ROS degrades membrane polyunsaturated fatty acids and produces 4hydroxylnonenal (4-HNE) and malondialdehyde (MDA) (Zhu et al., 2015). MDA is a highly unstable aldehyde which could induce oxidative stress by forming a covalent protein adduct which serves as a hallmark of oxidative stress in tissue injury (Chang et al., 2015).

Treatment with GSPE to STZ-induced diabetic nephropathy rats significantly decreased lipid peroxidation (L-MDA) in the diabetic nephropathy rats when compared with non-treated group. These results are in agreement with Liu et al. (2006). Who showed that, decreased L-MDA level in kidney tissue treated with GSPE compared to non-treated group. Also, GSPE provides significantly greater protection against free radicals and free radical induced lipid peroxidation and DNA damage than vitamin $\mathrm{C}, \mathrm{E}$ and $\beta$-carotene during the use of similar doses (Bagchi et al., 1998).

In diabetes, $\beta$-oxidation of fatty acids is stimulated by fatty acyl CoA oxidase enzyme which stimulated by low level of circulating insulin (Kumar et al., 2008). Increase of L-MDA formation is due to production of free radical species. These radicals attributed to a stimulated destruction of DNA, carbohydrates and lipids. This will lead to hyperglycemia and glucose autooxidation (Mansouri et al., 2011). GSPE may exert their effect via improving oxidative stress status (Liu et al., 2006).

Presented findings showed that, NF$\mathrm{kB}$ gene expression in kidney of STZ-induced diabetic nephropathy rats is significantly upregulated compared to normal control group. Similarly, Iwamoto et al. (2001) who reported that, in STZ-induced diabetes, NF$\mathrm{kB}$ was upregulated in renal cortical tissue. Also, Lal et al. (2001) observed that, advanced glycation end-products induced oxidative stress and upregulated $\mathrm{NFkB}$ in mesangial cells.

Administration of GSPE to STZinduced diabetic nephropathy rats significantly down regulated NF-kB gene expression in diabetic nephropathy rats when compared with non-treated group. These results are in agreement with Liu et al., (2012) and Sayed, (2012 and 2013) who showed that, GSPE is a naturally occurring antioxidant and could play an important role in the activity of several mitochondrial enzymes that are involved in the oxidation of glucose and ATP production. Therefore, the beneficial effects of GSPE on diabetes mellitus and diabetic nephropathy could be attributed to the combined anti-inflammatory/antioxidant effects and the metabolic regulations that include increasing of glucose oxidation and attenuation of NF- $\kappa \mathrm{B}$ activation.

In the present study, it is notable that GSPE has anti-inflammatory effects and a pivotal role in the treatment of DN. An increasing number of inflammatory signal pathways and cytokines are being investigated and deemed new molecular targets for treating DN. In the progress of diabetic nephropathy, certain pro-inflammatory cytokines and ROS become activated which induces mesangial cells to secrete type IV collagen, laminin and fibronectin that leading to glomerulosclerosis (Tam et al., 2009). The activation of NF-kB, monocyte chemoattractant protein-1 (MCP-1) and macrophage infiltration in the diabetic kidney were explored in a temporal manner. The active subunit of NF-kB p65 was elevated in the diabetic animals in association with increased MCP-1 gene expression and 
macrophage infiltration (Cha et al., 2005). The present study is consistent with these results, confirming that the anti-inflammatory activities of GSPE are mediated by downregulation of NF-kB gene expression resulting in reduced kidney tissue inflammation and tubulointerstitial nephritis.

\section{CONCLUSION:}

From the obtained results it could be concluded that, the experimental induction of diabetic nephropathy in male rats caused a significant increase in serum glucose, urea and creatinine concentrations as well as a significant increase in L-MDA level with a significant upregulation of NF-kB gene expression in kidney tissues. Also, there was a significant decrease in kidney tissue SOD activity and GSH level. however, GSPE treatment in STZ-induced diabetic nephropathy rats relieved all previous parameters towards its normal range so, these results confirm the strong antioxidant and anti-inflammatory effects of GSPE in STZinduced diabetic nephropathy.

\section{REFERRENCES:}

Abir T. El-Alfy, Amany A.E. Ahmed, Amal J. Fatani.2005. Protective effect of red grape seeds proanthocyanidins against

Akbarzadeh,

A.;Norouzian,D.;Mehrabi,M.R.;Jamsh idi,S.h. Farhangi , A.; Allah Verdi, A.;Mofidian,S.M. and Lame Rad,B.2007. Induction of diabetes by streptozotocin in rats, Indian Journal of Clinical Biochemistry, 22 (2): 6064.

Akram R, Hassan G, Mahdi H, Farahanaz D, Tavakol H. S, Farhad K. 2016. Tempol effects on diabetic nephropathy in male rats. J Renal Inj Prev. 5(2): 74-78.
Alarcon-Aguilar F., A. Fortis-Barrera, S. Angeles-Mejia, et al., 2010. Antiinflammatory and antioxidant effects of a hypoglycemic fructan fraction from Psacalium peltatum (HBK) Cass. in streptozotocin-induced diabetes mice, J. Ethnopharmacol., 132(2), 400-407.

Al-Faris NA, Al-Sawadi AD, and Alokail MS, 2010. Effect of Samah seeds supplementation

(Mesembryanthemum forsskalei Hochst) on liver enzymes and lipid profiles of streptozotocin (STZ)induced diabetic Wistar rats. Saudi Journal of Biological Sciences; 17:2328.

Alsaif, M.A. 2009. Beneficial Effects of Rutin and Vitamin C Co-administration in a streptozotocin-Induced Diabetes Rat Model of Kidney Nephrotoxicity. Pakistan Journal of Nutrition 8 (6): 745-754.

Bagchi D, Bagchi M, Stohs S, Das D, Ray S, Kuszynski C, etal. 2000.Free radicals and grape seed proanthocyanidin extract: importance in humsn health disease and prevention. Toxicology: 148:187-97

Bagchi D, Garg A, Krohn RL, Bagchi M, Bagchi DJ, Balmoori J, Stohs SJ. 1998. Protective effects of grape seed proanthocyanidins and selected antioxidants against TPA-induced hepatic and brain lipid peroxidation and DNA fragmentation, and peritoneal macrophage activation in mice. Gen. Pharmacol., 30: 771-776.

Bagchi K, Puri S.1998. Free Radicals and Antioxidants in Health and Disease. Eastern Mediterranean Health J; 4:350-60. 
Bagchi, D., Garg, A., Krohn, R.L., Bagchi, M., Tran, M.X. and Stohs, S.J. 1997. Oxygen free radical scavenging abilities of vitamins $\mathrm{C}$ and $\mathrm{E}$ and a grape seed proanthocyanidin extract in vitro. Res. Commun.Mol. Pathol. Pharmacol. 95: 179-189.

Bagchi, M.; Ray, S.D; Patel, D. and Bagchi, M. 2001. "Protection against drugand chemical-induced multiorgan toxicity by a novel IH636 grape seed proanthocyanidin extract". Drugs Exp.Clin. Res. ;27(1): 3-15.

Bao L, Zhaofeng Z, Xiaoqian D, Ye D, Yanfei J, Yujie L and Yong L.2015. Effects of grape seed proanthocyanidin extract on renal injury in type 2 diabetic rats. MOLECULAR MEDICINE REPORTS 11: 645-652.

Bhatti, F.; $\quad$ Mankhey, R.W.; $\quad$ Asico, L.; Quinn, M.T.; Welch, W.J. and Maric, C. 2005. Mechanisms of antioxidant and pro-oxidant effects of $\alpha$-lipoic acid in the diabetic and nondiabetic kidney. Kidney International, 67, 1371-1380.

Bukan, N.; Sancak, B.; Yavuz, O.; Koca, C.; Tutkun, F.; Ozcelikay, A. and Altan, N. 2003. lipid peroxidation and scavenining enzyme levels in the liver of streptozotocin-induced diabetic rats. vol 40, pp 447-450.

Cha DR, Kang YS, Han SY, Jee YH, Han KH, Kim HE, Han JY, Kim YS. 2005. Role of aldosterone in diabetic nephropathy.Nephrology, 10, S37S39.

Chabrashvili, T. et al. 2002. Expression and cellular localization of classic NADPH oxidase subunits in the spontaneously hypertensive rat kidney. 39, 269-274.
Chang, F X. Luo, W. Jiang, et al., 2015. Protective activity of salidroside against ethanol-induced gastric ulcer via the MAPK/NF-kappaB pathway in vivo and in vitro, Int. Immunopharmacol., 28(1), 604-615.

Chung, S.S.; Ho, E.C.; Lam, K.S.; Chung, S.K. 2003. Contribution of polyol pathway to diabetesinduced oxidative stress, J. Am. Soc. Nephrol., 14, S233-S236.

Daniel Eze E, Aliyu M, Yusuf T, Abubakar A. 2015. Effects of lycopene on kidney antioxidant enzyme activities and functions in streptozotocininduced diabetic Wistar rats. Cell Biology; 3(1): 1-13.

Erejuwa OO, 2012. Oxidative Stress in diabetes mellitus: is there arole for hypoglycaemicdrugs and/or antioxidants? Oxidativestress and diseases, Volodymyr I. Lushchak and Dmytro V.Gospodaryov (Ed.), ISBN: 978-953-51-0552-7; InTech

Farber, J.L.; Kyle, M.E. and Coleman, J.B. 1990. Mechanisms of cell injury by activated oxygen species. Lab Invest 62: 670-679.

Gallou, G.; Ruelland, A.; Campion, L. Maugendre; D.; Le Moullec, N.; Legras, B.; Allannic, H. and Cloarec, L. 1994. Increase in thiobarbituric acid-reactive substances and vascular complications in type 2 diabetes mellitus. Diabetes Metab, 20:258-264.

Gao Z, Liu G, Hu Z, et al. (2014): Grape seed proanthocyanidin extract protects from cisplatin-induced nephrotoxicity by inhibiting endoplasmic reticulum stress induced apoptosis. Mol Med Rep. 9:801-807.

Gavin, J.R.; Alberti, K.J.; Davidson, M.B.; DeFronzon, R.A.; Drash, A. ;Gabbe, 
S.G.; Genuth, S.; Harris, M.I.; Kahn, R.; Keen, H.; Knowler, W.C.; Lebovitz, H.; Maclaren, N.K.; Palmer, J.P.; Raskin, P.; Rizza, R.A. and Stern, M.P. 1997. Report of the expert comitte on the diagnosis and classification of Diabetes Mellitus. Diabetes Care. 20: 1183-1197.

Gumieniczek, A., 2005. Effects of repaglinide on oxidative stress in tissues of diabetic rabbits. Diab.Res. Clin.Pract., 68: 89-95.

Ha H, Hwang IA, Park JH, Lee Hb. 2008. role of reactive oxygen species in the pathogenesis of diabetic nephropathy. Diabetes Res Clin Pract, 13:S42-S50.

Haidara MA, Mikhailidisc DP, Rateba MA et al.2008. Evaluation of the effect of oxidative stress and vitamin $\mathrm{E}$ supplementation on renal function in rats with streptozotocin-induced type 1 diabetes. J Diabetes Complications.

Hertog, M.G.L. and Hollman, P.C.H. 1996. Potential health effects of the dietary flavonol quercetin. Eur J Clin Nutr 50:63-71.

Huang, T.H.; Peng, G.; Kota, B.P.; Li, Q.G.; Yamahara, J.; Roufogalis, B.D. and Li, Y. 2005. Anti-diabetic action of Punica granatum flower extract: activation of PPAR- $\mathrm{Y}$ and identification of active component. Toxical. Pharm., 207: 160 - 169.

Ismail, R.S. and Abd El-Gawad, S.H. 2010. potential Effect of Egyptian Anna Apple Pomace ( Malus domestica , Rosaceae ) supplementation on kidney function, Liver function and lipid profile of diabetic rats .World Journal of Dairy \& Food Science ; 5(1):5866.
Iwamoto $\mathrm{M}$, Mizuiri S, Tanimoto $\mathrm{H}$ et al. 2001. Nuclear factor-kB activation in streptozotocin induced diabetic rats kidneys. J Am Soc Nephrol; 12: 838a.

Jacob S., K. Rett, E. J.Henriksen, and H.U.Haring, 1999. Thioctic acid-effects on insulin sensitivity and glucose metabolism. Biofactors, vol. 10, no. 23, pp.169-174.

Jagdish, K. and Nehal, S. 2011. Comparison effect of Pioglitazone and Glimepiride alone on renal function marker in experimentally induced renal damage in diabetic rats. Journal of Applied Pharmaceutical Science 01 (03); 72 76.

Jagdish, K.; Mehul, S. and Nehal, S. 2010. Glimepiride reduces on experimentally induced ischemia/reperfusion in diabetic rats. Volume: I: Issue-2,276-285.

Jovanovic, S.V.; Steenken, S.; Simic, M.G. and Hara, Y. 1998. Antioxidant properties of flavonoids: reduction potentials and electron transfer reactions of flavonoid radicals. In Flavonoids in Health and Disease. C Rice Evans, L Packer (eds). NewYork; Marcel Dekker, pp 137161.

Kakadiya, J.; Shah, M. and Shah, N. 2010. Glimepiride reduces on experimentally induced is chemical reperfusion in diabetic rats. IJABPT, 1:276-285.

Kakkar, P., Das, B., Viswanathan, P.N. 1984. A modified spectrophotometric assay of superoxide dismutase. Indian $\mathrm{J}$. Biochem Biophys 21, 130-132.

Kaneto, H.; Fujii, J.; Kamada, T. and Taniguchi, N. 1995. Apoptotic cell death triggered by nitric oxide in 
pancreatic beta-cells. Diabetes. 44: 733-738.

Kedziora-Kornatowska KZ, Luciak M, and Paszkowski J. 2000. Lipid peroxidation and activities of antioxidant enzymes in the diabetic kidney: Effect of treatment with angiotensin convertase inhibitors. International Union of Biochemistry and Molecular Biology Life; 49: 303307.

Kumar G, Banu GS, Murugesan AG. 2008. Effect of Helicteres isora bark extracts on heart antioxidant status and lipid peroxidation in streptozotocin diabetic rats. J Appl Biomed 6: 89-95.

Kumar R, Kar B, Dolai N, Bala A, and Haldar PK, 2012. Evaluation of antihyperglycaemic and antioxidant properties of Streblusas- perLour against streptozotocin-induced diabetes in rats. Asian Pacific Journal of Tropical Disease; 2(2): 139-143.

Kumar, G.; Murugesan, A.G. and Rajasekara Pandian, M. 2006. Effect of Helicteres isora bark extract on blood glucose and hepatic enzymes in experimental diabetes. Indian J. Exp. Biol. 22(3): 211-225.

Lal M, Brismar H, Eklof AC, Aperia A. 2001. Advanced glycationendproducts induce oxidative stress and activate NF-kB, PKCb1, and TGF- $\beta 1$ in mesangial cells. J Am Soc Nephrol;12: 840a.

Lal, S.S.; Suk la, Y.; Singh, A.; Andriyas, E.A. and Lall, A.M. 2009. Hyperuricemia, High Serum Urea and Hypoproteinemia are the Risk Factor for Diabetes. Asian Journal of Medical Sciences 1(2): 33-34.

Lee YA, Cho EJ, Yokozawa T.2008. Effects of proanthocyanidin preparations on hyperlipidemia and other biomarkers in mouse model of type 2 diabetes. $\mathbf{J}$ Agr Food Chem 56: 7781-7789.

Liu, Y.N., Shen, X.N. and Yao, G.Y. 2006. Effects of grape seed proanthocyanidin extracts on experimental diabetic nephropathy in rats. Wei. Sheng.Yan. Jiu. 35: 703705.

Livak, K.J., Schmittgen, T.D. 2001. Analysis of relative gene expression data using real-time quantitative $\mathrm{PCR}$ and the $2^{-\Delta \Delta C}$ T Method. Methods 25(4), 402408.

Mansouri E, Khorsandi L, Moaiedi MZ. 2015. Grape Seed Proanthocyanidin Extract Improved some of Biochemical Parameters and Antioxidant Disturbances of Red Blood Cells in Diabetic Rats. Iran J Pharm Res 14: 329.

Mansouri E, Panahi M, Ghaffari MA, Ghorbani A 2011. Effects of grape seed proanthocyanidin extract on oxidative stress induced by diabetes in rat kidney. Iran Biomed J 15: 100-106.

Mesbah, L., Soraya, B., Narimane, S., Jean, P.F. 2004. protective effect of flavonides against the toxicity of vinblastine cyclophosphamide and paracetamol by inhibition of lipid peroxydation and increase of liver glutathione. Haematol 7 (1), 59-67.

Mogensen, C. E., Christensen, C. K. \& vittinghus, E.1983. The stages in diabetic renal disease. With emphasis on the stage of incipient diabetic nephropathy. Diabetes 32 (Suppl. 2), 64-78.

Mohora M, Vîrgolici B, Paveliu F, Lixandru D, Muscurel C, Greabu M. 2006. Free radical activity in obese patients with 
type 2 diabetes mellitus. Rom $\mathbf{J}$ Intern Med; 44: 69-78.

Nazima B, Manoharan V, Miltonprabu S.2015. Grape seed proanthocyanidins ameliorates cadmium-induced renal injury and oxidative stress in experimental rats through the up-regulation of nuclear related factor 2 and antioxidant responsive elements. Biochem Cell Biol. 93(3):210-226.

Obrosova, I.G.; Fathallah, L.; Liu, E. and Nourooz Zadeh, J. 2003. Early oxidative stress in the diabetic kidney: effect of DL-alpha-lipoic acid. Free Radic. Biol. Med., 15; 34(2): 186-195.

Pacher, P., Obrosova, I. G., Mabley, J. G. \& Szabó, C.2005.Role of nitrosative stress and peroxynitrite in the pathogenesis of diabetic complications. Emerging new therapeutical strategies. Curr.Med. Chem. 12, 267-275.

Paglia DE, Valentine WN.1967. Studies on the quantitative and qualitative characterization of erythrocyte glutathione peroxidase. $\mathrm{J}$ Lab Clin Med.70 (1) :158-69.

Papaharalambus CA, Griendling KK. 2007. Basic mechanisms of oxidative stress and reactive oxygen species in cardiovascular injury. Trends Cardiovasc Med; 17: 48-54.

Pinent M., Blaym M., Blade C , Salvado M. J, Arola L, and A. Arde V.2004.Grape Seed-Derived Procyanidins Have an Antihyper- glycemic Effect in Streptozotocin-Induced Diabetic Rats and Insulinomimetic Activity in Insulin- Sensitive Cell Lines Endocrinology 145(11):4985-4990.
Ramanathan, M.; Jaiswal, A.K. and Bhattacharya, S.K. 1999. Superoxide dismutase, catalase jand glutahiones peroxidase activities in the brain of streptozotocin induced diabetic rats. Indian. J.Exp.Biol.; 37: 182-183.

Rolo A. P. and C. M. Palmeira, 2006. Diabetes and mitochondrial function: role of hyperglycemia and oxidative stress, Toxicol. Appl. Pharmacol., 212(2), 167-178.

Sakami, W. and Harrington, H. 1963. Amino acid metabolism, Ann. Rev. Biochem., 32: 355-398.

Sayed A. A., Ferulsinaic acid attenuation of diabetic nephropathy.2013. European Journal of Clinical investigation, vol. 43 , no. 1 , pp.56-63

Sayed A.A. 2012. Thymoquinone and proanthocyanidin attenuation of diabetic nephropathy in rats.Eur Rev Med Pharmacol Sci, 16:808-815.

Shiose, A. et al. 2001. A novel superoxideproducing $\mathrm{NAD}(\mathrm{P}) \mathrm{H}$ oxidase in kidney. J. Biol. Chem. 276, 14171423.

Shukla K, Dikshit P, Tyagi MK, Shukla R, and Gambhir JK, 2012.Ameliorative effect of Withaniacoagulans on dyslipidaemia and oxidative stress in nicotinamide-streptozotocin induced diabetes mellitus. Food and Chemical Toxicology, 50: 3595-3599.

Siddiqui MH, Al-Whaibi MH, and Basalah MO, 2011. Role of nitricoxide in tolerance ofplants to abiotic stress. Protoplasma; 248: 447-455.

Singh U, Singh S, and Kochhar A, 2012.Therapeutic potential of antidiabeticnutraceuticals.Phytopharm acology; 2(2):144-169. 
Suryawanshi, N.P.; Bhutey, A.K.; Nagdeote, A.N.; Jadhav, A.A. and Manoorkar, G.S. 2006. Study of lipid peroxide and lipid profile in diabetes mellitus. Indian Journal of Clinical Biochemistry, 21 (1) 126-130.

Tam FW, Riser BL, Meeran K, et al. 2009. Urinary monocyte chemoattractant protein-1 (MCP-1) and connective tissue growth factor $(\mathrm{CCN} 2)$ as prognostic markers for progression of diabetic nephropathy. Cytokine 47: 37-42.

Tietz, N.W. 1986. Textbook of clinical chemistery. WB saunders, Philadelphia, pp 1271-1281.

Tietz, N.W. ED. 1990. Clinical guide to laboratory tests. 2 ND ED.philadelphia: WB Saunders; 566.

Tietz, N.W. ed. 1995. Clinical guide to laboratory tests. 3rd ed. Philadeiphia.WB Saunders; 268-273.

Tirgar P, Jadav P, Sheth D, Desai T, Tirgar PR, Jadav PD, and Sheth MDB, 2010. Therapeutic role of anti-oxidant properties of Emblicaofficinalis(amla) in streptozotocin induced type 1 diabetic rats. Pharmacology online; 1:728-743.

Toba, H., Sawai, N., Morishita, M., Murata, S., Yoshida, M., Nakashima, K., Morita, Y., Kobara, M. and Nakata, T. 2009. Chronic treatment with recombinant human erythropoietin exerts renoprotective effects beyond hematopoiesis in streptozotocininduced diabetic rat. Eur. J. Pharmacol. 612: 106-114.

Williamson, J.R.; Chang, K.; Kilo, C. and Tilton, R.G. 1993. Hyperglycemic pseudohypoxia land diabetic complications. Diabetes. 42: 801-813.
Yadav, P.; Sarkar, S. and Bhatnagar, D. 1997. Lipid peroxidation and antioxidant enzymes in erythrocytes and tissues in aged diabetic rats. Ind J Exp Biol 35: 389-392.

Zhu, T L. Wei, X. Chang, et al., 2015. Effects of Salidroside on M [pp'yocardial Injury In Vivo In Vitro via Regulation of Nox/ NF-kappaB/AP1 Pathway, Inflammation, 38(4), 1589-1598. 